Original article

\title{
Determinant factors of drug resistant tuberculosis in Iran, a case control study
}

\author{
Mahdi Afshari ${ }^{\mathrm{a}}$, Mohsen Aarabi ${ }^{\mathrm{b}}$, Mohammadreza Parsaee ${ }^{\mathrm{c}}$, Asghar Nezammahalleh $^{\mathrm{c}}$, \\ Mahmood Moosazadeh ${ }^{\mathrm{d}, *}$
}

a Department of Community Medicine, School of Medicine, Zabol University of Medical Sciences, Zabol, Iran

b Department of Family Medicine, School of Medicine, Mazandaran University of Medical Sciences, Sari, Iran

${ }^{\mathrm{c}}$ Health Deputy, Mazandaran University of Medical Sciences, Sari, Iran

${ }^{\mathrm{d}}$ Health Sciences Research Center, Addiction Institute, Mazandaran University of Medical Science, Sari, Iran

\section{A R T I C L E I N F O}

\section{Keywords:}

Tuberculosis

Drug resistant

Case-control

\begin{abstract}
A B S T R A C T
Introduction: Drug resistance is one of the critical aspects had to be considered in the tuberculosis control program. Factors related to drug resistance are different in geographic regions and vary during the time. The present study aims to determine the risk factors of drug resistance among TB patients in northern of Iran. Methods: In this case control study, 22 cases (drug resistant TB patients) and 88 controls (TB patients selected out of those with successive treatment) were randomly selected from a cohort of TB patients in Northern of Iran. The required information was collected from TB registration software in Mazandaran University of Medical Sciences.

Results: Of 22 drug resistant TB patients, resistance to isoniazid, rifampin and also multidrug resistance were observed in 10(9.1\%), 3(2.7\%) and $9(8.2 \%)$ respectively. Moreover, $22.2 \%$ of MDR cases, $66.7 \%$ of rifampin resistant cases and $40 \%$ of isoniazid resistant patients had experienced previous TB treatment $(p=0.363)$. Logistic regression models showed that the history of previous treatment was significantly associated with drug resistance $(\mathrm{OR}=16.55,95 \% \mathrm{CI}=2.83-96.89$ ).

Conclusion: History of previous anti-TB treatment can be a determinant factor for TB drug resistance.
\end{abstract}

\section{Introduction}

Tuberculosis (TB) is an infectious disease and the top nine cause of death in the world. ${ }^{1-3}$ Although anti TB treatment is available in all countries, the mortality is higher than HIV/AIDS. Different causes are responsible for this high mortality. ${ }^{4}$

The incidence rate of TB in 2016 in Iran has been reported as of $14(11-18)$ per 100,000 population. Multidrug resistance (MDR) is one of the main challenges against the TB control program and a serious threat for human being. ${ }^{3,5}$ In 2016, about 8.1(7.3-8.9)/100,000 of the total population in the world were experienced drug resistance $4.1 \%$ (2.8-5.3) of which were new cases and 19\% (9.8-27) had history of previous treatment. In 2016, the incidence of MDR in EMRO region among all TB patients, new cases and those with history of previous treatment was estimated as of $6.2(4.7-7.8) / 100,000,4.2 \%(1.7-6.7)$ and $17 \%(14-19)$ population respectively. In this year, the incidence of MDR cases in Iran was reported as of $0.25(0.14-0.36)$ per 100,000 population. ${ }^{3}$ In China, the frequency of MDR and XDR cases among TB patients was $16.7 \%$ and $3.4 \%$ respectively with an increasing trend from $2005 .{ }^{6}$ Results of a meta-analysis showed that frequency of XDR TB among new and re-treatment cases in Nigeria was $6 \%{ }^{4-8}$ and $32 \%(20-44)$ respectively. ${ }^{7}$

The treatment success rate among drug resistant TB patients in the world, EMRO region and Iran in 2014 was estimated as of 54\%, 65\% and $58 \%$ respectively. The corresponding rates for XDR-TB patients in the world as well as the EMRO region were $30 \%$ and $42 \%$ respectively. ${ }^{4}$ Since these patients have poor response to treatment and low treatment success, they can spread the infection in the communities and more affected the healthy populations. ${ }^{8}$ Other adverse outcomes such as death, treatment default, relapse and treatment failure are also associated with drug resistance. In the European countries, history of the previous treatment has been reported as a major risk factor for the drug resistance among TB patients. ${ }^{9}$ Results of a multivariate logistic regression analysis on the data collected from Zimbabwean TB patients showed the history of caring an MDR TB patient as a risk factor for MDR TB. ${ }^{10}$

\footnotetext{
* Corresponding author. Health Sciences Research center, Addiction Institute, Mazandaran University of Medical Sciences, Sari, Iran.

E-mail address: mmoosazadeh1351@mazums.ac.ir (M. Moosazadeh).
} 
The above facts indicate that drug resistance should be taken into consideration as one of the main components of the TB control program. To identify all risk factors of the MDR TB, analytic and observational studies should be carried out. Although several studies have been conducted in different parts of the world, no similar evidence was observed in the northern provinces in Iran (such as Mazandaran province). Because the determinant factors of drug resistance are various in different areas and times, we performed this study to detect the risk factors associated with such adverse outcome in this region.

\section{Materials and methods}

The present research was a case-control study carried out among TB patients registered in the TB control centers of Mazandaran province, Iran from 2005 to 2017. Cases were all 22 patients with drug resistance selected by census method. In order to increase the power of the study, four patients with treatment success were randomly selected per each case. Cases and controls were individually matched based on the year of incidence and the treatment center.

Required information such as gender, age, residence area, history of imprisonment, close contact with TB patient and previous TB treatment and also type of TB, drug reactions and HIV status was obtained from the TB registry software of the Mazandaran University of Medical Sciences in the excel format. The ethical considerations were met based on the Helsinki declaration. To respect privacy, the patients' name and national codes were excluded from the dataset.

The collected data were transferred into the SPSS version 16 . Descriptive statistics was performed using mean, standard deviation and percent frequency. Comparing the factors between cases and controls was carried out using independent $\mathrm{T}$ test. Multivariate logistic regression models were applied to detect the predictors of the drug resistance. P-value less than 0.05 was considered statistically significant.

\section{Results}

In the present study, 22 cases and 88 controls were investigated. Mean (SD) age of the cases and controls was 46.82(18.76) and 45.90(20.65) respectively ( $\mathrm{p}=0.849)$. Of cases, $10(9.1 \%)$ were just isoniazid resistant, $3(2.7 \%)$ were just rifampin resistant and $9(8.2 \%)$ were multi-drug resistant.

Table 1 shows that frequency of $35-54$ years age group $(\mathrm{p}=0.846)$,

Table 1

Comparing the investigated factors between cases and controls.

\begin{tabular}{|c|c|c|c|c|c|}
\hline Variables & & Total & Case; n (\%) & $\begin{array}{l}\text { Control; n } \\
(\%)\end{array}$ & P-value \\
\hline \multirow[t]{3}{*}{ Age group } & $<35$ & 42 & $8(36.4)$ & $34(38.6)$ & 0.864 \\
\hline & $35-54$ & 30 & $7(31.8)$ & $23(26.1)$ & \\
\hline & $>54$ & 38 & $7(31.8)$ & $31(35.2)$ & \\
\hline \multirow[t]{2}{*}{ Gender } & Male & 74 & $17(77.3)$ & $57(64.8)$ & 0.264 \\
\hline & Female & 36 & $5(22.7)$ & $31(35.2)$ & \\
\hline \multirow[t]{2}{*}{ Residence area } & Urban & 66 & $14(63.6)$ & $52(59.1)$ & 0.697 \\
\hline & Rural & 44 & $8(36.4)$ & $36(40.9)$ & \\
\hline \multirow[t]{2}{*}{ imprisonment } & No & 103 & $20(90.9)$ & $83(94.3)$ & 0.625 \\
\hline & Yes & 7 & $2(9.1)$ & $5(5.7)$ & \\
\hline \multirow[t]{2}{*}{ Nationality } & Iranian & 105 & $22(100)$ & $83(94.3)$ & 0.581 \\
\hline & Non-Iranian & 5 & 0 & $5(5.7)$ & \\
\hline \multirow{3}{*}{$\begin{array}{l}\text { History of close } \\
\text { contact with TB } \\
\text { patient }\end{array}$} & No & 64 & $10(45.5)$ & $54(61.4)$ & 0.196 \\
\hline & Yes & 17 & $6(27.3)$ & $11(12.5)$ & \\
\hline & Unknown & 29 & $6(27.3)$ & $23(26.1)$ & \\
\hline \multirow[t]{3}{*}{ HIV status } & No & 49 & $10(45.5)$ & $39(44.3)$ & 0.775 \\
\hline & Yes & 2 & 0 & $2(2.3)$ & \\
\hline & Unknown & 59 & $12(54.5)$ & $47(53.4)$ & \\
\hline \multirow[t]{2}{*}{ Drug complication } & No & 76 & $15(68.2)$ & $61(69.3)$ & 0.918 \\
\hline & Yes & 34 & $7(31.8)$ & $27(30.7)$ & \\
\hline \multirow[t]{2}{*}{ Previously treated } & No & 101 & $15(68.2)$ & $86(97.7)$ & $<0.001$ \\
\hline & Yes & 9 & $7(31.8)$ & $2(2.3)$ & \\
\hline
\end{tabular}

Table 2

Associated factors for drug resistance among TB patients based on the logistic regression models.

\begin{tabular}{|c|c|c|c|c|}
\hline Variables & & OR & CI 95\% & P-value \\
\hline \multirow[t]{3}{*}{ Age group } & $<35$ & - & - & - \\
\hline & $35-54$ & 1.25 & $0.32-4.83$ & 0.743 \\
\hline & $>54$ & 0.94 & $0.25-3.58$ & 0.931 \\
\hline \multirow[t]{2}{*}{ Gender } & Male & - & - & - \\
\hline & Female & 0.56 & $0.16-2.01$ & 0.377 \\
\hline \multirow[t]{2}{*}{ Residence area } & Urban & - & - & - \\
\hline & Rural & 0.93 & $0.31-2.84$ & 0.905 \\
\hline \multirow[t]{2}{*}{ imprisonment } & No & - & - & - \\
\hline & Yes & 1.00 & $0.12-8.37$ & 0.997 \\
\hline \multirow[t]{2}{*}{ Nationality } & Iranian & - & - & - \\
\hline & Non-Iranian & Omitted & Omitted & Omitted \\
\hline \multirow{3}{*}{$\begin{array}{l}\text { History of close contact with TB } \\
\text { patient }\end{array}$} & No & - & - & - \\
\hline & Yes & 1.91 & $0.42-8.55$ & 0.400 \\
\hline & Unknown & 1.06 & $0.25-4.40$ & 0.938 \\
\hline \multirow[t]{3}{*}{ HIV status } & No & - & - & - \\
\hline & Yes & empty & empty & empty \\
\hline & Unknown & 1.78 & $0.51-6.18$ & 0.361 \\
\hline \multirow[t]{2}{*}{ Drug complication } & No & - & - & - \\
\hline & Yes & 0.86 & $0.26-2.80$ & 0.798 \\
\hline \multirow[t]{2}{*}{ Previously treated } & No & - & - & - \\
\hline & Yes & 16.55 & $2.83-96.89$ & 0.002 \\
\hline
\end{tabular}

males $(p=0.264)$, urban residents $(p=0.697)$, HIV negative patients ( $p=0.775)$, Iranians $(p=0.581)$, patients with history of imprisonment $(\mathrm{p}=0.625)$, close contact $(\mathrm{p}=0.196)$ and drug adverse effect ( $p=0.918$ ) were higher among cases than controls. However, all of these differences were not significant. While, cases significantly more than controls had history of previous treatment ( $p<0.001)$.

Results of multivariate logistic regression models for determining the risk factors of drug resistance showed that the odds ratio for history of previous treatment was estimated as of $16.55(95 \%$ CI: $2.83-96.89$ ). The odds ratios for the other investigated variables such as age, gender, history of imprisonment, close contact, previous treatment and also residence area and HIV status were not statistically significant (Table 2). Based on the Nagelkerke R test, these variables just explained the $26.4 \%$ of the odds of drug resistance.

\section{Discussion}

To have success in Tb control, all factors associated with the treatment outcomes should be identified. These factors might be different in different communities. Cohort studies with large sample sizes are the best studies for detecting such factors, but these types of researches had not been carried out in northern parts of Iran such as Mazandaran province. Therefore, we aimed to conduct this study in this area using a completely registered and followed up population.

Results of the present study showed that middle aged TB patients compared to younger cases had $25 \%$ higher chance of drug resistance. We also observed that the odds of drug resistance among women, rural residences and patients with adverse drug reactions was respectively $44 \%, 7 \%$ and $14 \%$ lower than that among men, urban residences and those without adverse drug effect. In addition, patients having close contact with other TB patients and patients with unknown status of HIV infection had respectively $91 \%$ and $78 \%$ higher chance of drug resistance compared to those without close contact as well as HIV negative patients. However, all of the above associations were not statistically significant. The only factor showed significant relationship with drug resistance was history of previous treatment which caused 16.5 folds increased odds of occurring drug resistance among TB patients.

A study carried out in one of the cities in the central of Iran (Arak) showed that $7.8 \%$ of TB patients had drug resistance and history of previous treatment and age under 45 were risk factors of drug resistance. It should be noted that other factors such as nationality, residence area, HIV infection, close contact and degree of sputum smear 
positivity were not significantly associated with drug resistance. ${ }^{11}$ These results are similar to the results of the current study.

Based on the results of a study conducted in a referral TB hospital in the capital of Iran, immigration and refugee status as well as history of previous treatment were the most risk factors for drug resistance while close contact, diabetes mellitus, cigarette smoking and positive BCG scar were not associated with drug resistance. ${ }^{12}$

A systematic review investigated the risk factors of drug resistant TB in the European countries using 29 primary studies reported higher risk of drug resistance among men, patients with history of previous treatment, foreigners, those older than 65 years and HIV positive patients. ${ }^{9}$

Another systematic review estimated the prevalence of drug resistant TB in four countries (Iran, Iraq, Turkey and Pakistan) as of $16 \%(11-20)$. In this region, male patients, those aged under 45 and having history of previous treatment had higher risk of drug resistance. ${ }^{13}$

In Zimbabwe, monitoring of patients by health care personnel was identified as a protective factor against multi drug resistance. ${ }^{10}$ In northern India, $71.1 \%$ of TB patients were resistant to at least one of the anti-TB drugs $53.3 \%$ of whom had MDR TB which was significantly associated with previous history of TB treatment and familial contact, cigarette and alcohol use. ${ }^{14}$ Prevalence of drug resistance to at least one drug among all TB patients, new cases and re-treatment cases in Dalian, China was reported as of $31.1 \%, 24.1 \%$ and $43.4 \%$ respectively. Corresponding figures for MDR was $10.1 \%, 5.8 \%$ and $17.7 \%$ respectively. These cases were significantly associated with previous treatment and age over $30 .{ }^{15}$ All of the above mentioned studies were in keeping with the results of the present study regarding the relationship between drug resistance and history of previous treatment.

The limitation of the current research is low number of the cases or drug resistant TB patients so that the number of cases in some of the subgroups was zero.

Our study showed that history of treatment with anti-TB drugs is a predictor of drug resistance. To control the rate of drug resistance among TB patients, the direct observe treatment should be performed in high quality to reduce the incomplete treatment by patients. Moreover, the rate of false negative results in the sputum smear assessments during the treatment should be minimized. Such mistakes can divert the appropriate response and early diagnosis of drug resistance cause losing the opportunities. Therefore it is recommended to investigate the sputum smears during the treatment by two independent lab technicians. Easy access of treatment centers to lab centers with sputum culture and antibiogram facilities is another strategy make all patients be assessed regarding drug resistance at the beginning of the treatment.

\section{Authors' contributions}

$\mathrm{MM}$ and MA contributed in the design of research, analysis of data and writing of manuscript. MP and AN contributed to the collection data. MA, MP and ANmade substantial contributions to interpretation of data. All authors read and approved the final manuscript.

\section{Conflicts of interest}

The authors declare that they have no Conflict of interest.

\section{Acknowledgment}

The authors thank to the deputy for health of Mazandaran University of Medical Sciences, Iran for their kindly cooperation for data access. The authors thank to Zabol University of Medical Sciences, Iran for their financial support.

\section{Appendix A. Supplementary data}

Supplementary data to this article can be found online at https:// doi.org/10.1016/j.cegh.2018.09.006.

\section{References}

1. Moosazadeh M, Khanjani N, Nasehi M, Bahrampour A. Predicting the incidence of smear positive tuberculosis cases in Iran using time series analysis. Iran J Public Health. 2015;44(11) 1526-34.

2. Rezai MS, Tabrizi R, Haghdoost AA, et al. Estimating the prevalence of positive Tuberculin skin test reactions in general population and high-risk groups: a metaanalysis. Int J Prev Med. 2017;8:97.

3. Who. Global tuberculosis report. Available at: http://www.who.int/tb/publications/ global_report/en/; 2017.

4. Velayati AA, Farnia P, Farahbod AM. Overview of drug-resistant tuberculosis worldwide. Int J Mycobacteriol. 2016;5(Suppl 1):S161.

5. Moosazade M, Jamshidi M, Amiresmaili M, Nezammahalleh A. A comparison of directly observed therapy and self-administered therapy strategies in treatment of pulmonary tuberculosis: a cohort study in north of Iran, middle-east. J Sci Res. 2012:11(7):873-880.

6. Liao S, Cai C, Huo FM, et al. Trends in drug-resistant tuberculosis in China: data from a clinical tuberculosis centre. Int J Tubercul Lung Dis. 2017;21(9):990-995.

7. Onyedum CC, Alobu I, Ukwaja KN. Prevalence of drug-resistant tuberculosis in Nigeria: a systematic review and meta-analysis. PLoS One. 2017;12(7):e0180996.

8. Moosazadeh M, Bahrampour A, Nasehi M, Khanjani N. The incidence of recurrence of tuberculosis and its related factors in smear-positive pulmonary tuberculosis patients in Iran: a retrospective cohort study. Lung India. 2015;32(6):557-560.

9. Faustini A, Hall AJ, Perucci CA. Risk factors for multidrug resistant tuberculosis in Europe: a systematic review. Thorax. 2006;6(2):1 158-163.

10. Muchena G, Shambira G, Masuka N, et al. Determinants of multidrug resistance among previously treated tuberculosis patients in Zimbabwe. Int J Tubercul Lung Dis. 2014;21(11):1167-1172 2017.

11. Farazi A, Sofian M, Zarrinfar N, Katebi F, Hoseini SD, Keshavarz R. Drug resistance pattern and associated risk factors of tuberculosis patients in the central province of Iran. Caspian J Intern Med. 2013;4(4):785-789.

12. Baghaei P, Tabarsi P, Chitsaz E, Novin A, Alipanah VN, et al. Risk factors associated with multidrug-resistant tuberculosis. Tanaffos. 2009;8(3):17-21.

13. Jimma W, Ghazisaeedi M, Shahmoradi L, et al. Prevalence of and risk factors for multidrug-resistant tuberculosis in Iran and its neighboring countries: systematic review and meta-analysis. Rev Soc Bras Med Trop. 2017;50(3):287-295.

14. Sinha P, Srivastava GN, Gupta A, Anupurba S. Association of risk factors and drug resistance pattern in tuberculosis patients in north India. $J$ Global Infect Dis. 2017;9(4):139-145.

15. Lv XT, Lu XW, Shi XY, Zhou L. Prevalence and risk factors of multi-drug resistant tuberculosis in Dalian, China. J Int Med Res. 2017;45(6):1779-1786. 